\title{
Sleep deprivation and hallucinations. A qualitative study of military personnel
}

Ståle Pallesen, Olav K. Olsen, Elisabeth M. Eide, Benedicte Nortvedt, Janne Grønli, Frank Larøi, Morten Nordmo \& Fride E. Glomlien

To cite this article: Ståle Pallesen, Olav K. Olsen, Elisabeth M. Eide, Benedicte Nortvedt, Janne Grønli, Frank Larøi, Morten Nordmo \& Fride E. Glomlien (2018) Sleep deprivation and hallucinations. A qualitative study of military personnel, Military Psychology, 30:5, 430-436, DOI: 10.1080/08995605.2018.1478561

To link to this article: https://doi.org/10.1080/08995605.2018.1478561

册 Published online: 02 Aug 2018.

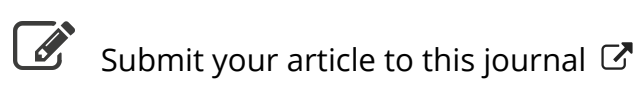

Щ Article views: 171

View Crossmark data ¿ 


\title{
Sleep deprivation and hallucinations. A qualitative study of military personnel
}

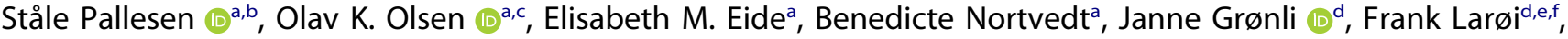 \\ Morten Nordmo ${ }^{\mathrm{a}}$, and Fride E. Glomlien ${ }^{\mathrm{a}}$

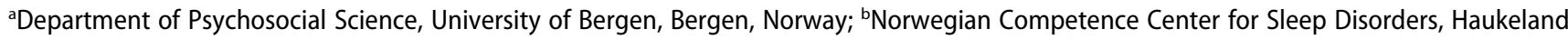 \\ University Hospital, Bergen, Norway; ${ }^{C}$ Royal Norwegian Naval Academy, Norway; ${ }^{\mathrm{D} D e p a r t m e n t}$ of Biological and Medical Psychology, \\ University of Bergen, Bergen, Norway; ${ }^{2}$ NORMENT - Norwegian Centre of Excellence for Mental Disorders Research, University of Oslo, \\ Norway; fPsychology and Neuroscience of Cognition Research Unit, University of Liège, Liège, Belgium
}

\begin{abstract}
Much anecdotal evidence suggests that sleep deprivation not only impairs performance, but also brings about other extraordinary effects like hallucinations. However, knowledge about how sleep deprivation may trigger hallucinations is limited. To qualitatively describe hallucinatory experiences during sleep deprivation 12 male military officers from the Norwegian Armed Forces who all had experienced at least one sleep loss-induced hallucinatory experience were recruited. Data were collected and analyzed by semi-structured interviews and thematic analysis. This resulted in the identification of three distinct main themes: (1) Modalities, (2) circumstances/triggers and (3) reactions to hallucinations. Hallucinations were experienced in several modalities (visual, auditory and multi-modality), although visual hallucinations seemed to dominate. Typical reported circumstances/triggers were sleep loss, physical exhaustion, time-of-day, low calorie intake, mental exhaustion and lack of external stimuli (low sensory and social input, boring situations, and monotonous activity). Negative emotions were dominant during the hallucinatory episodes. Often some reasoning and checking on behalf of the officers were necessary to differentiate between real percepts and hallucinations. In some cases the hallucinations caused erroneous actions. Retrospectively, most officers viewed their hallucinatory experiences in light of positive emotions and several emphasized having learned something from them. The results are discussed in relation to the existing literature and suggestions for future studies are outlined.
\end{abstract}

\section{ARTICLE HISTORY}

Received 19 July 2017

Accepted 10 March 2018

\section{KEYWORDS}

Hallucinations; sleep deprivation; modalities; triggers; reactions
What is the public significance of this article? - In all 12 male officers were interviewed regarding hallucinatory experiences during sleep deprivation. Most hallucinations seemed to be visual and typical triggers were severe sleep loss, mental and physical exhaustion, nighttime, lack of food and lack of external stimulation. Although negative emotions and some erroneous actions were experienced during the hallucinations, most officers look back on the hallucinations with positive emotions and report having learned something from them.

Numerous studies attest to the negative effects of sleep deprivation affecting a wide range of cognitive tasks, such as simple reaction time (Dinges et al., 1994), sustained attention (Pilcher, Band, Odle-Dusseau, \& Muth, 2007), working memory (Forest \& Godbout, 2000), long-term memory (Drummond et al., 2000), visuomotor performance (Van Dongen, Baynard, Maislin, \& Dinges, 2004), decision making (Harrison \& Horne, 1999), logic reasoning (Blagrove, Alexander, \& Horne, 1995), response inhibition (Drummond, Paulus, \& Tapert, 2006), non- verbal intelligence (Linde \& Bergström, 1992), moral reasoning (Olsen, Pallesen, \& Eid, 2010) and divergent thinking (Horne, 1988).

Taken together these studies strongly suggest that sleep loss significantly impairs brain functioning, a notion that has been supported by brain-imaging studies (Mander et al., 2008; Stricker, Brown, Wetherell, \& Drummond, 2006; Wang, Chen, Yao, Pan, \& Sun, 2016). Early theories explaining the negative effects of sleep deprivation on performance put much emphasis on lapses (periods of unresponsiveness due to micro-sleep) which were assumed to increase with the duration of sleep loss (Williams, Lubin, \& Goodnow, 1959). Later theories took additionally in consideration moderating factors such as motivation, situation and circadian rhythms (Doran, Van Dongen, \& Dinges, 2001; Kjellberg, 1977).

Much anecdotal evidence suggests that sleep deprivation also brings about other effects than performance decrements. Hallucinations have in this regard been reported and are regarded as one the most extraordinary impacts of sleep deprivation and can be defined as "any 
percept-like experience which (a) occurs in the absence of an appropriate stimulus, (b) has the full force or impact of the corresponding actual (real) perception and (c) is not amenable to direct and voluntary control by the experiencer" (Slade \& Bentall, 1988, p. 23). They may occur in any sensory modality (Carter, 1992). A notable example is the case of Randy Gardner who in order to gain entry to Guinness Book of World Records stayed awake for 264 hours. On the fourth day he started to hallucinate, perceiving a street sign as a person (Ross, 1965). Still, few scientific studies on the effects of sleep deprivation on hallucinations have been conducted. Whereas a search in Web of Science on June 27, 2017 combining the terms "sleep deprivation" and $\operatorname{cog} n^{*}$ as title words provided 175 hits, a corresponding search combining the terms "sleep deprivation" and halluc* provided only one hit.

One of the first studies (Williams, Morris, \& Lubin, 1961) that systematically assessed hallucinations during sleep deprivation involved 70 to 100 hours of sleep loss. About half of the subjects reported visual hallucinations after 65 hours, which seemed to progress from blurred vision after about 30 hours of sleep loss to full-blown hallucinations occurring about 65 to 90 hours into the sleep deprivation period. In a study with 66 British soldiers, three troops either obtained 3 hours, 1.5 hours or no sleep each day during a 9-day exercise. Three of the soldiers in the second and in the last condition hallucinated, four during nighttime and two during the daytime. The hallucinations occurred after 66 hours of sleep loss and many of them were very vivid (Belenky, 1979). In another of the few studies on this topic, 10 subjects were kept awake for 48 or 72 hours and six of the subjects reported both perceptual distortions and hallucinations. The perceptual distortions occurred earlier during the sleep deprivation phase than the hallucinations. These incidents further showed a circadian component with the lowest occurrence in the late afternoon/early evening and highest occurrence in the late night/early morning (Babkoff, Sing, Thorne, Genser, \& Hegge, 1989).

Hallucinations during sleep loss have further been studied in athletes participating in long-lasting competitions. In a study of 12 solo sailors participating in a race lasting for 6-8 days with a mean self-reported sleep per day of 4.1 hours, four reported auditory hallucinations and one reported visual hallucinations during the race (Hurdiel et al., 2012). In a study of 17 runners running between 27 and 44 hours in an ultramarathon, four reported visual hallucinations; three during the second night of the race, and one during the test after the race (Hurdiel et al., 2015).
Overall these studies indicate that sleep deprivation needs to be of a certain magnitude in order to elicit hallucinations and that a circadian component may be in play. Still, the knowledge about the nature of hallucinations caused by sleep loss is very limited both when it comes to the nature/content of hallucinations, additional circumstantial factors other than sleep deprivation that may trigger hallucinations and how officers deal with/react to hallucinations. Studies on the nature of hallucinations in military contexts are of high relevance for personnel regarding recognition and reactions to such events, especially since these may have implications for behavior and decisions that might have serious operational consequences (Staal \& Stephenson, 2006). Against this background, we wanted to explore the phenomena and experiences related to sleep lossinduced hallucinations. As military personnel often experience extensive sleep deprivation (Krueger, 1989) we decided to conduct a qualitative study with 12 officers addressing the following question: How does Norwegian military officers experience sleep deprivation-induced hallucinations and under which circumstances do these occur?

\section{Methods}

\section{Sample}

All officers $(n=10)$ in a special forces class at the Royal Norwegian Naval Academy and two highly experienced officers known to the authors were asked to participate in the present study as these were assumed to have experienced extensive sleep deprivation and concomitant hallucinations. All agreed and confirmed that they at least once, due to sleep deprivation, had hallucinated in a military context (which was the eligibility criterion). The 12 officers were all males and ranged in age from 23 to 49 years and all had served in international operations.

\section{Procedure}

A semi-structural interview guide was initially made by the authors. The interview guide included a definition of hallucinations in line with Slade and Bentall (1988) which was read aloud to the officers. Further, the guide contained questions about how many times the officers had experienced total sleep deprivation (no sleep for at least 24 hours) and partial sleep deprivation ( $<5$ hours sleep) (Pilcher \& Huffcutt, 1996) for at least four consecutive days. This was followed by questions pertaining to experienced hallucinations (circumstances, 
content, duration, validation of the hallucinatory experience, senses involved, time of day, immediate and long-term effects). The interviews were taped and were conducted between February and March, 2017. The authors FEG, EME and BN conducted the interviews and transcribed them individually. Before the interviews started, all officers were provided a consent form and all agreed to participate. The project was approved by the Norwegian Data Protection Official (project no. 51,802) and the data was collected in line with APA ethical standards.

\section{Analysis}

A thematic analysis (TA) was used on the data. In this specific case, an essentialist or realist method of TA was used in which reports are assumed to reflect experiences, meanings and the reality of participants. Themes were identified by being essential for the research questions and agreed upon by more than one author (FEG, EME and $\mathrm{BN}$ ) in the data analytic process. As the data analysis was not guided by any specific theoretical perspective, the analysis should be regarded as an inductive/bottom-up approach. Furthermore, a semantic, rather than a latent theme identification was used as the themes were identified within the explicit or surface meaning of the data (Braun \& Clarke, 2006). Identification of themes followed the standard procedure described by Braun and Clarke (2006): (1) Getting familiarized with the data (transcription and reading of the interviews), (2) generating initial ideas (initial/tentative coding of interviews in terms of different topics/ issues linking these to relevant extracts), (3) searching for potential overarching themes and sub-themes, (4) reviewing themes (reviewing coded data extracts and consideration of the validity of individual themes in relation to the whole data set, (5) defining and naming themes (define and refine themes) and (6) producing the report. Part 1-3 of the process was conducted individually by three of the authors (FEG, EME and $\mathrm{BN}$ ), whereas part $4-5$ was conducted by the same authors in parallel reaching consensus and by such ensuring analyst triangulation (Patton, 1999).

\section{Results}

The officers had experienced total sleep deprivation between 10 and 180 times, and partial sleep deprivation between 3 and 100 times. They had hallucinated between one and 25 times during sleep deprivation.

A total of three overarching themes were identified, each with three, four and four sub-themes, respectively. The themes and sub-themes are presented in Table 1 .

\section{Theme 1: Modality}

It seemed that most hallucinations were visual, some were task-related whereas others were more surrealistic/bizarre: "And some are more extreme. For example, when studying a map together with two others. You look at the map and the others, and they seem to have... They have their body but with wolf heads. They talk, but still have the wolf heads" (officer 10).

A few officers also reported auditory hallucinations, however there were more uncertainties associated with these. Some stated that it was difficult to know if the experiences were hallucinations, "misperceptions" (officer 2) or "if it's just self-fulfilling prophecies" (officer 1). "I am unsure if I actually did hear anything or not, however, visual things can easily be confirmed/disconfirmed" (officer 11).

Some officers reported multi-modal hallucinations: "I was blindfolded. And there was constant background noise. And after a while I had the impression that I was at sea. I sat on the floor in a room... The impression was that I was in a boat at sea and that the boat was sinking" (officer 3).

\section{Theme 2: Circumstances/triggers}

The second main theme identified concerned circumstances/triggers of the hallucinations. In terms of the physical state of the officers, sleep loss was always emphasized as a trigger: "There were some days without sleep. We were very tired... The last 24-36 hours there had been an intense effort. And then there was no sleep, we had not slept for days" (officer 12). Another physical

Table 1. Identified main themes and sub-themes.

\begin{tabular}{llll}
\hline Main themes: & \multicolumn{1}{c}{ Modality } & \multicolumn{1}{c}{ Circumstances/triggers } & \multicolumn{1}{c}{ Reactions } \\
\hline Sub-themes & Visual & $\begin{array}{l}\text { Physical state } \\
\text { (sleep loss, time-of-day, physical strain, low calorie intake) }\end{array}$ & $\begin{array}{l}\text { Immediate affective responses } \\
\text { (negative effects, positive change) } \\
\text { Checking validity }\end{array}$ \\
& Auditory & $\begin{array}{l}\text { Mental state } \\
\text { (between sleep-wakefulness) }\end{array}$ & Retrospective affects \\
& $\begin{array}{l}\text { External stimuli } \\
\text { (reduced sensory and social input) } \\
\text { Activity } \\
\text { (boring situations, monotonous activity) }\end{array}$ & Learning \\
\hline
\end{tabular}


state related triggered was the time of day: "It happens normally at night, a little after 3 at night and you are at your most tired state that you most easily imagine things in the surroundings" (officer 4). Most officers described the physical strain prior to hallucinating as "heavy" or "hard". A large majority of the officers also reported low calorie intake as a precursor to hallucinations: "I have experienced longer periods without sleep, but with food, but cannot recall hallucinating then" (officer 7).

Concerning the mental state as a trigger several officers pointed to being in a state between sleep and wakefulness: "One feels that one is about to sleep, in between sleep and wake. It must have been in such transient state where one is half wake and fantasy intrudes" (officer 5).

The third sub-theme related to circumstances/triggers concerned the environment. Hallucinations seemed to predominate in situations with few external stimuli: "One needs a certain amount of stimuli in order to avoid hallucinating. If I get too little sensory input, it has turned into hallucinations. And since we work a lot during nighttime, it is a challenge to obtain sufficient stimulation" (officer 3). Social stimuli related to this were emphasized as important: "It might happen that one deals with a task completely alone, while the others are sleeping. That's in a way the most difficult situations when one is really sleep deprived" (officer 4).

Also, situations with low activity seemed to be related to hallucination proneness: "Boring situations. Sitting calmly, or very monotonous activity. It has never happened if I have high pulse, even if I am really tired. Or am engaged in general activity where I have to activate my head and such things, then it very rarely occurs" (officer 8). Still some reported hallucinations also during high intensity activity: "We have been keeping at it for a while, without little food and sleep and we run alone and had to reach certain place by ourselves"... A big BMW is parked in the middle of the forest" (officer 10).

\section{Theme 3: Reactions}

Reactions comprised the third main theme. Immediate affective responses typically consisted of negative affects such as "helpless" (officer 2 and 12), "afraid" (officer 3 and 7), "frustrating" (officer 2), "paranoid" (officer 5), "embarrassed" (officer 11) and "resigned" (officer 3). The following excerpt illustrates this well: "I was very afraid. Felt completely alone in the world" (officer 3). Some was however able to regard the hallucination as a positive change: "Oh - this was a bit funny... And it was a bit odd and something to spend time on, since the circumstances were quite boring, as you are just lying in one place for a long time. So all changes are a little bit like - oh lovely" (officer 8).

When it comes to checking the validity of the hallucinations, this was in some instances not necessary as some officers immediately knew they were having hallucinatory experiences: "I did realize it, but they were there for some time. And then it just faded away" (officer 10). Still, the majority reported that it sometimes could be difficult to differentiate between hallucinations and real perception and that some reasoning in some cases was needed to conclude: "After some time I realized that...That car could not be there, as the place was not drivable" (officer 10). In some instances the hallucinations also caused erroneous actions: "We were walking in a line. When the person in front of me turned left I continued straight ahead... His backpack that I had stared at for hours had just got stuck in my mind, so it was there although he turned 90 degrees...I was not aware of it until the soldier behind me touched me and wondered what I was doing" (officer 7). Although most seemed to be behaviorally affected by hallucinations, some tried to ignore/fight them: "Pull yourself together. Hence, do something. Regain the control" (officer 12).

In aftermath the majority of the officers viewed the hallucinations in a positive way using descriptors such as "interesting" (officer 3), "funny" (officer 4 and 11), "pleasurable and fun-filled" (officer 9). It was emphasized that the hallucinations were "humorous" in retrospect and "things to talk about in the aftermath" (officer 4). Still, some did express concern about their experience: "It is not a good thing to hallucinate when watching over the rest of the lads. It's not favorable" (officer 12).

Learning was the final sub-theme identified and several officers reported to have learned something from their hallucinatory experiences: "I am conscious of it in regard of future occasions where I have not slept for a while, that my eyesight can be disturbed" (officer 5). Likewise, others stated that the experiences caused them "to look twice" (officer 7 and 10), "not taking everything for face value" (officer 7) and "a humbleness in terms of things related to sleep" (officer 1).

\section{Discussion}

The aim of this study was to examine the phenomena and experiences related to sleep loss-induced hallucinations. Most of the hallucinations reported in the present study were visual. This seems to be in line with most previous reports (Babkoff et al., 1989; Belenky, 1979; Hurdiel et al., 2015; Williams et al., 1961) although this is at odds with one study suggesting that auditory hallucinations may dominate during sleep deprivation 
(Hurdiel et al., 2012). Overall, the findings indicate that the visual modality is more sensitive to hallucinations due to sleep loss compared to other modalities. According to the state-dissociation theory (Mahowald \& Schenck, 1991, 1992) hallucinations may be regarded as wakeful dreams (Mahowald, Woods, \& Schenck, 1998) and the visual dominance of the reported hallucinations is as such in line with notions of dreams as primarily visual (Hobson \& Stickgold, 1994; Symons, 1993). Another explanation of the visual dominance regarding the reported hallucinations may be that hallucinations related to other sensory systems are harder to validate in a sleep deprived state.

The second main theme entailed the circumstances/ triggers of hallucinations. These comprised among others the physical state of the officers. Sleep deprivation seemed to have to reach a certain level in order to elicit hallucinations, which are in accordance with case observations (Ross, 1965) and more systematic studies (Belenky, 1979; Williams et al., 1961). This suggests that the risk of hallucinations increases with increased sleep propensity, which further would be in line with the state-dissociation theory (Mahowald \& Schenck, 1991, 1992). Some officers reported that sleep lossinduced hallucinations seemed to occur following strenuous physical effort. Due to perceptual habituation effects (Rensink, 2002) it seems conceivable that contrast effects, mimicking sensory deprivation, may occur after such efforts. This would be consistent with West (1975) who claims that a sustained level and variety of sensory input normally is required to inhibit emergence of percepts or memory traces from within the brain itself. The latter is also in line with other results from the present study indicating that situations with little stimulation, including lack of social stimulation, may pose a risk of hallucinations in sleep-deprived subjects. In this regard, Belenky (1979) states that reducing social isolation and increasing sensory simulation would improve performance during sustained operations. The fact that low levels of social and sensory stimulation during sleep deprivation seem to be triggers of hallucinations has some striking reminiscence with hallucinatory experiences that have been reported during studies of sensory deprivation (Daniel, Lovatt, \& Mason, 2014). The hallucinatory experiences during sensory deprivation have among others been explained in accordance with the faulty reality monitoring hypothesis (Bentall, 1990) and may suggest that sleep loss impairs the ability to differentiate between internal and external generated stimuli.

Food deprivation was also mentioned as a trigger for hallucinations, a notion that has received attention previously (Phillips, 1978). In this regard it has been suggested that hyper-excitation of the dopaminergic system may play a role in generating hallucinatory experiences (Blom, 2010) in such circumstances. Several officers reported that hallucinations prevailed during nighttime. This is in agreement with previous studies (Babkoff et al., 1989; Belenky, 1979). If hallucinations represent dreams during wakefulness (Mahowald \& Schenck, 1991, 1992), a circadian component related to their occurrence would be expected as the rapid-eye movement sleep (dream sleep) is regulated by the circadian pacemaker in the brain and its propensity is elevated at night during sleep deprivation (Wurts \& Edgar, 2000).

The third main theme concerned reactions to the hallucinations. Dysphoric affects dominated during the hallucinations, which seem to be common among nonclinical subjects experiencing hallucinations (Larøi \& Van Der Linden, 2005). However, the affective responses to the hallucinations seemed to be dominated by positive affects retrospectively. Many officers took actions in order to validate the content of their hallucinations, which has been reported previously among military personnel (Belenky, 1979). Finally, many of the officers mentioned that they had learned something from their hallucinatory experiences.

In terms of practical implications, knowledge about triggers and information about the nature of sleep lossinduced hallucinatory experiences should be considered a topic for inclusion in the training of military personnel. Systematically debriefing and discussions about hallucinatory experiences and their consequences following military exercises including severe sleep deprivation, may also be implemented. As leaders have a special responsibility for ensuring optimal rest and restitution of personnel under their command (Miller, Shattuck, \& Matsangas, 2011) we specifically suggest that the topic of sleep loss-induced hallucinations should be incorporated in military sleep leadership/management programs (Gunia, Sipos, LoPresti, \& Adler, 2015).

\section{Limitations and strengths}

In terms of limitations it should be noted that the generalizability is restricted due to the relatively small number of informants. Also, sleep deprivation and hallucinatory experiences were reported retrospectively and may as such be influenced by recall biases. Regarding assets of the present study it is, to the best of our knowledge, the first that addresses sleep deprivation and concomitant hallucinations in military personnel using a qualitative design. Further, the present study identified additional triggers for hallucinations 
(e.g. food deprivation) in military personnel and also report on the potential for erroneous actions as a consequence of sleep loss-induced hallucinations.

\section{Conclusions and future studies}

Severe sleep loss seems to elicit hallucinations, mainly of visual modality. Nighttime, previous strenuous activity, lack of stimulation and food deprivation were reported to act in synchronicity with sleep loss in terms of evoking hallucinations. Most officers reported immediate negative affects to the hallucinations, whereas retrospectively the hallucinations were regarded in a more positive way. It is suggested that military personnel should learn about the nature of sleep loss-induced hallucinations.

Future studies should investigate whether there are individual differences regarding susceptibility to sleep loss-induced hallucinations. Further, experimental studies should systematically investigate how different moderators (e.g. time of day, previous activity, level of stimulations and nutritional status) interact with sleep loss in eliciting hallucinations. The temporal nature of sleep loss-induced hallucinations should also be examined in more detail (how many hours of sleep deprivation are required, are hallucinations experienced long after the sleep deprivation period is over and, if so, are there individual differences, etc.). Finally, studies focusing on efforts to prevent and counteract sleep loss-related hallucinations should be prioritized, for example in terms of recovery and leadership.

\section{ORCID}

Ståle Pallesen (10) http://orcid.org/0000-0002-5831-0840 Olav K. Olsen (D) http://orcid.org/0000-0002-7674-7229 Janne Grønli (D) http://orcid.org/0000-0002-2781-3533

\section{References}

Babkoff, H., Sing, H. C., Thorne, D. R., Genser, S. G., \& Hegge, F. W. (1989). Perceptual distortions and hallucinations reported during the course of sleep deprivation. Perceptual and Motor Skills, 68, 787-798. doi:10.2466/ pms.1989.68.3.787

Belenky, G. L. (1979). Unusual visual experiences reported by subjects in the British Army study of sustained operations. Military Medicine, 144, 695-696. doi:10.1093/milmed/ 144.10.695

Bentall, R. P. (1990). The illusion of reality: A review and integration of psychological research on hallucinations. Psychological Bulletin, 107, 82-95.

Blagrove, M., Alexander, C., \& Horne, J. A. (1995). The effects of chronic sleep reduction on the performance of cognitive tasks sensitive to sleep deprivation. Applied Cognitive Psychology, 9, 21-40. doi:10.1002/(ISSN)1099-0720

Blom, J. D. (2010). A dictionary of hallucinations. New York, NY: Springer-Verlag.

Braun, V., \& Clarke, V. (2006). Using thematic analysis in psychology. Qualitative Research in Psychology, 3, 77-101. doi:10.1191/1478088706qp063oa

Carter, J. L. (1992). Visual, somatosensory, olfactory, and gustatory hallucinations. Psychiatric Clinics of North America, 15, 347-358.

Daniel, C., Lovatt, A., \& Mason, O. J. (2014). Psychotic-like experiences and their cognitive appraisal under short-term sensory deprivation. Frontiers in Psychiatry, 5, article 106.

Dinges, D. F., Douglas, S. D., Zaugg, L., Campbell, D. E., McMann, J. M., Whitehouse, W. G., ... Orne, M. T. (1994). Leukocytosis and natural killer cell function parallel neurobehavioral fatigue induced by 64 hours of sleep deprivation. Journal of Clinical Investigation, 93, 19301939. doi:10.1172/JCI117184

Doran, S. M., Van Dongen, H. P. A., \& Dinges, D. F. (2001). Sustained attention performance during sleep deprivation: Evidence of state instability. Archives Italiennes De Biologie, 139, 253-267.

Drummond, S. P. A., Brown, G. G., Gillin, J. C., Stricker, J. L., Wong, E. C., \& Buxton, R. B. (2000). Altered brain response to verbal learning following sleep deprivation. Nature, 403, 655-657. doi:10.1038/35001068

Drummond, S. P. A., Paulus, M. P., \& Tapert, S. F. (2006). Effects of two nights sleep deprivation and two nights recovery sleep on response inhibition. Journal of Sleep Research, 15, 261-265. doi:10.1111/ j.1365-2869.2006.00535.x

Forest, G., \& Godbout, R. (2000). Effects of sleep deprivation on performance and EEG spectral analysis in young adults. Brain and Cognition, 43, 195-200.

Gunia, B. C., Sipos, M. L., LoPresti, M., \& Adler, A. B. (2015). Sleep leadership in high-risk occupations: An investigation of soldiers on pacekeeping and combat missions. Military Psychology, 27, 197-211. doi:10.1037/mil0000078

Harrison, Y., \& Horne, J. A. (1999). One night of sleep loss impairs innovative thinking and flexible decision making. Organizational Behavior and Human Decision Processes, 78, 128-145. doi:10.1006/obhd.1999.2827

Hobson, J. A., \& Stickgold, R. (1994). Dreaming - a neurocognitive approach. Consciousness and Cognition, 3, 1-15. doi:10.1006/ccog.1994.1001

Horne, J. A. (1988). Sleep loss and divergent thinking ability. Sleep, 11, 528-536.

Hurdiel, R., Monaca, C., Mauvieux, B., McCauley, P., Van Dongen, H. P. A., \& Theunynck, D. (2012). Field study of sleep and functional impairments in solo sailing races. Sleep and Biological Rhythms, 10, 270-277. doi:10.1111/ sbr.2012.10.issue-4

Hurdiel, R., Peze, T., Daugherty, J., Girard, J., Poussel, M., Poletti, L., ... Theunynck, D. (2015). Combined effects of sleep deprivation and strenuous exercise on cognitive performances during The North Face (R) Ultra Trail du Mont Blanc (R) (UTMB (R)). Journal of Sports Sciences, 33, 670674. doi:10.1080/02640414.2014.960883

Kjellberg, A. (1977). Sleep deprivation and some aspects of performance. III. Motivation, comment and conclusions. Waking and Sleeping, 1, 149-153. 
Krueger, G. P. (1989). Sustained work, fatigue, sleep loss and performance. A review of the issues. Work and Stress, 3, 129-141. doi:10.1080/02678378908256939

Larøi, F., \& Van Der Linden, M. (2005). Nonclinical participants' reports of hallucinatory experiences. Canadian Journal of Behavioural Science-Revue Canadienne Des Sciences Du Comportement, 37, 33-43. doi:10.1037/h0087243

Linde, L., \& Bergström, M. (1992). The effects of one night without sleep on problem solving and immediate recall. Psychological Research, 54, 127-136.

Mahowald, M. W., \& Schenck, C. H. (1991). Status dissociatus-a perspective on states of being. Sleep, 14, 69-79.

Mahowald, M. W., \& Schenck, C. H. (1992). Dissociated states of wakefulness and sleep. Neurology, 42, 44-52.

Mahowald, M. W., Woods, S. R., \& Schenck, C. H. (1998). Sleeping dreams, waking hallucinations, and the central nervous system. Dreaming, 8, 89-102. doi:10.1023/B: DREM.0000005899.59224.17

Mander, B. A., Reid, K. J., Davuluri, V. K., Small, D. M., Parrish, T. B., Mesulam, M. M., ... Gitelman, D. R. (2008). Sleep deprivation alters functioning within the neural network underlying the covert orienting of attention. Brain Research, 1217, 148-156. doi:10.1016/j.brainres.2008.04.030

Miller, N. L., Shattuck, L. G., \& Matsangas, P. (2011). Sleep and fatigue issues in continuous operations: A survey of $\mathrm{U}$. S. army officers. Behavioral Sleep Medicine, 9, 53-65. doi:10.1080/15402002.2011.533994

Olsen, O. K., Pallesen, S., \& Eid, J. (2010). The impact of partial sleep deprivation on moral reasoning in military officers. Sleep, 33, 1086-1090.

Patton, M. Q. (1999). Enhancing the quality and credibility of qualitative analysis. Health Services Research, 34, 1189-1208.

Phillips, R. W. (1978). Religious revelations and bovine ketosis (a nonsacred cow). Perspectives in Biology and Medicine, 21, 398-405.

Pilcher, J. J., Band, D., Odle-Dusseau, H. N., \& Muth, E. R. (2007). Human performance under sustained operations and acute sleep deprivation conditions: Toward a model of controlled attention. Aviation Space and Environmental Medicine, 78, B15-B24.

Pilcher, J. J., \& Huffcutt, A. I. (1996). Effects of sleep deprivation on performance: A meta-analysis. Sleep, 19, 318-326.
Rensink, R. A. (2002). Change detection. Annual Review of Psychology, 53, 247-277. doi:10.1146/annurev. psych.53.100901.135125

Ross, J. J. (1965). Neurological findings after prolinged sleep deprivation. Archives of Neurology, 12, 399-403.

Slade, P. D., \& Bentall, R. P. (1988). Sensory deception: Towards a scientific analysis of hallucinations. London, UK: Croom Helm.

Staal, M. A., \& Stephenson, J. A. (2006). Operational psychology: An emerging subdiscipline. Military Psychology, 18, 269-282. doi:10.1207/s15327876mp1804_2

Stricker, J. L., Brown, G. G., Wetherell, L. A., \& Drummond, S. P. A. (2006). The impact of sleep deprivation and task difficulty on networks of fMRI brain response. Journal of the International Neuropsychological Society, 12, 591-597. doi:10.1017/S1355617706060851

Symons, D. (1993). The stuff that dreams aren't made of. Why wake-state and dream-state sensory experinences differ. Cognition, 47, 181-217.

Van Dongen, H. P. A., Baynard, M. D., Maislin, G., \& Dinges, D. F. (2004). Systematic interindividual differences in neurobehavioral impairment from sleep loss: Evidence of traitlike differential vulnerability. Sleep, 27, 423-433.

Wang, L., Chen, Y., Yao, Y., Pan, Y., \& Sun, Y. (2016). Sleep deprivation disturbed regional brain activity in healthy subjects: Evidence from a functional magnetic resonanceimaging study. Neuropsychiatric Disease and Treatment, 12, 801-807. doi:10.2147/NDT.S99644

West, U. (1975). A clinical and theoretical overview of hallucinatory phenomena In R. In K. Siegel \& U. West (Eds.), Hallucinations. Behavior, experience, and theory (pp. 287311). New York, NY: John Wiley \& Sons.

Williams, H. L., Lubin, A., \& Goodnow, J. J. (1959). Impaired performance with acute sleep loss. Psychological Monographs, 73(484). doi:10.1037/h0093749

Williams, H. L., Morris, G., \& Lubin, A. (1961). Illusions, hallucinations and sleep loss. Acta Psychologica, 19, 805806. doi:10.1016/S0001-6918(61)80372-7

Wurts, S. W., \& Edgar, D. M. (2000). Circadian and homeostatic control of rapid eye movement (REM) sleep: Promotion of REM tendency by the suprachiasmatic nucleus. Journal of Neuroscience, 20, 4300-4310. 